\title{
Glycogen Storage Disease Type 1b: Microsomal Glucose-6-Phosphatase System in Two Patients with Different Clinical Findings
}

\author{
KUNIAKI NARISAWA, ${ }^{(23)}$ HIROMI OTOMO, YUTAKA IGARASHI, NOBUHIRO ARAI, \\ MASATOSHI OTAKE, KEIYA TADA, AND TAKESHI KUZUYA \\ Department of Pediatrics [K.N., H.O., Y.I., N.A., M.O., K.T.], Tohoku University School of Medicine, Sendai 980, \\ Japan, Department of Medicine [T.K.], Jichi Medical School, Tochigi-Ken 329-04, Japan
}

\begin{abstract}
Summary
The basic defect in glycogen storage disease (GSD) type 1b was investigated in two patients: one, (Y.S.), a severely affected infant and the other, (Y.M.), an adult with mild clinical symptoms. The enzymatic studies on liver needle biopsy specimens from the two patients indicated that glucose-6-phosphate (G-6-P) phosphohydrolase activity of the "intact microsomes" was partially deficient (20\% of that in controls) in Y.M. and undetectable in Y.S. Activities of G-6-P phosphohydrolase in the disrupted microsomes of Y.S. and Y.M. are higher than those in the disrupted microsomes of controls (12.60 $\mu \mathrm{mole} / \mathrm{min} / \mathrm{g}$ liver in Y.S., 9.18 in Y.M. and 6.26 \pm 1.22 , mean \pm S.D. in controls). Our study also shows that PPi phosphohydrolase activities of the "intact microsomes" from both patients $(6.07 \mu \mathrm{mol} / \mathrm{min} / \mathrm{g}$ liver in Y.S. and 5.36 in Y.M.) were greater than those of the controls $(3.23 \pm 0.77 \mu \mathrm{mole} / \mathrm{min} / \mathrm{g}$ wet weight liver). These results indicate that the G-6-P translocase was the locus of the defect in both patients with GSD type $1 \mathrm{~b}$. Clinical symptoms and enzymatic studies suggest that the clinical severity of this disorder depends on the level of residual activities of G-6-P translocase. Kinetic studies showed an abnormally high $\mathrm{Km}$ of the residual G-6-P translocase in Y.M., suggesting a structural gene mutation. The systematic assay method for glucose-6-posphatase system, which requires only $15 \mathrm{mg}$ of liver tissues, is also described.
\end{abstract}

\section{Abbreviations}

G-6-P, glucose-6-phosphate

GOT, glutamic oxaloacetic transaminase

GPT, glutamic pyruvic transaminase

GSD, glycogen storage disease

M-6-P, mannose-6-phosphate

PAS, periodic acid-Schiff strain

PPi, pyrophosphate

TPN, total parenteral nutrition

UH, untreated liver homogenates

Two groups of GSD type 1 have been recognized. GSD type la patients show an absence of glucose-6-phosphatase activity (EC. 3.1.3.9) in liver specimens. Patients with GSD type $1 b$ have no enzyme defect in vitro, but the clinical findings are relatively indistinguishable from those of GSD type la $(21,22)$. The accumulation of hepatic glycogen and the result of glucose test using a double isotope technique (19) in GSD type lb patients suggest that the glucose-6-phosphatase is not functional in vivo. The fundamental defect in this was not understood for years.

In 1978 we reported that a basic defect in GSD type 1b was located in the G-6-P transport system of the microsomal membrane, based on the findings that the glucose-6-phosphatase activity was highly latent in the fresh liver homogenates $(11,14)$.
Furthermore, earlier observations of normal hepatic glucose-6phosphatase activity in these patients can be explained as a result of freezing the tissue, which causes disruption of the microsomal membrane $(11,14)$.

Hepatic glucose-6-phosphatase is part of a multicomponent system of the endoplasmic reticulum. In 1975 Arion et al. (3) postulated that at least two components of the endoplasmic reticulum participate in the process of G-6-P hydrolysis: (1) a G-6-P specific translocase that shuttles G-6-P across the membrane and (2) a relatively nonspecific phosphohydrolase, phosphotransferase, located in the luminal surface of the membrane. Subsequently the same groups (5) reported that the glucose-6-phosphatase system consisted of an additional transport system distinct from that moving G-6-P; i.e., phosphate (Pi) translocase which mediates $\mathrm{Pi}$ efflux out of the cisternae of the endoplasmic reticulum. Identification of the basic defect in GSD type $1 b$ requires assays for both G-6-P translocase and Pi translocase of intact microsomes. Recently Lange et al. (12) demonstrated that the defect is located indeed at G-6-P translocase. This finding was based on the results of activities of both G-6-P phosphohydrolase and PPi phosphohydrolase on intact microsomes from a type $\mathrm{lb}$ patient.

The purpose of this report is to compare the activities of the components for the hydrolysis of G-6-P between two cases of GSD type $1 b$. Micromethods for identification of the basic defect in GSD type 1, which can be applied to needle-biopsy specimens, are also described.

\section{CASE REPORTS}

Patient Y.S. is a 8-month-old boy, the second child of healthy unrelated parents. The older sister with GSD type $\mathrm{lb}$ was reported previously $(11,14)$. The patient, whose birth weight was $3.7 \mathrm{~kg}$, was born after a normal pregnancy and delivery. At 2 months of age the patient was admited to our hospital because of an enlarged liver. Upon admission the patient was well-nourished. The abdomen was moderately distended, the liver was palpable $5 \mathrm{~cm}$ below the costal margin, and no splenomegaly was observed. Initial laboratory studies revealed a normal urinalysis, the hemoglobin $8.6 \mathrm{~g} / 100 \mathrm{ml}$, and leukocyte count $5700 / \mathrm{mm}^{3}$ with a differential of $10 \%$ neutrophiles, $85 \%$ lymphocytes, $2 \%$ eosinophiles and $3 \%$ monocytes. The levels of blood glucose and lactate after a 4-h fast were $23 \mathrm{mg} / 100 \mathrm{ml}$ and $39.7 \mathrm{mg} / 100 \mathrm{ml}$, respectively. Serum GOT was $68 \mathrm{IU} /$ liter, GPT $34 \mathrm{IU} /$ liter, triglyceride $175 \mathrm{mg} / 100$ $\mathrm{ml}$, and cholesterol $119 \mathrm{mg} / 100 \mathrm{ml}$. The values of the uric acid, electrolytes, urea nitrogen, total protein and alkaline phosphatase in serum were within the normal ranges. Persistent diarrhea, 1020 times per day, developed soon after admission. Dietary and/or antibiotics treatments were not effective for diarrhea. TPN, supplying about $100 \mathrm{kcal} / \mathrm{kg} /$ day, was started 3 wk after admission.

During the TPN therapy, an improvement in the biochemical findings and a decrease in the liver size were noted. At 4 months 
Table 1. Hepatic glucose-6-phosphate (G-6-P) phosphohydrolase activities ( $\mu$ mole Pi/min/g wet weight) from patients with glycogen storage disease (GSD) type $1 b$ and $1 a$, and controls

\begin{tabular}{|c|c|c|c|c|c|}
\hline \multirow[b]{2}{*}{ Subject } & \multirow[b]{2}{*}{ Age } & \multicolumn{3}{|c|}{ G-6-P phosphohydrolase activity } & \multirow[b]{2}{*}{ Latency $^{2}$} \\
\hline & & Untreated homogenates & "Intact microsomes"1 & Disrupted homogenates & \\
\hline \multicolumn{6}{|l|}{ GSD lb } \\
\hline Patient Y.S. & $8 \mathrm{M}$ & 0.50 & 0.00 & 12.60 & 100.0 \\
\hline Patient Y.M. & $25 \mathrm{Y}$ & 1.52 & 0.85 & 9.18 & 90.7 \\
\hline \multicolumn{6}{|l|}{ GSD la } \\
\hline 1 & $11 \mathrm{M}$ & 0.18 & & 0.18 & \\
\hline 2 & $9 \mathbf{M}$ & 0.09 & & 0.10 & \\
\hline \multicolumn{6}{|l|}{ Control } \\
\hline 1 & adult & 3.66 & 3.47 & 5.88 & 41.0 \\
\hline 2 & $1 \mathrm{Y}$ & 5.22 & 4.91 & 7.75 & 36.6 \\
\hline 3 & $11 \mathrm{M}$ & 4.34 & 4.08 & 6.18 & 34.0 \\
\hline 4 & $5 Y$ & 4.75 & 4.48 & 6.22 & 28.0 \\
\hline 5 & adult & 3.42 & 3.27 & 4.26 & 23.2 \\
\hline 6 & adult & 5.66 & 5.30 & 7.29 & 27.3 \\
\hline
\end{tabular}

\footnotetext{
${ }^{1}$ Calculated using the equation of Arion et al. (5) (see "Materials and Methods")
}

${ }^{2}$ Latency is defined as $\left[1-\frac{\text { activity in "intact microsomes" }}{\text { activity in disrupted homogenates }}\right] \times 100$.

of age, the TPN was discontinued and an oral administration of a lactose free milk containing dextro-maltose and soluble starch was initiated and given every $3 \mathrm{~h}$. The liver and the spleen were enlarged progressively and fasting hypoglycemia $(22 \mathrm{mg} / 100 \mathrm{ml}$ after $4 \mathrm{~h}$ of fasting), hypertriglycerides $(272 \mathrm{mg} / 100 \mathrm{ml})$ and hyperuricemia $(11.3 \mathrm{mg} / 100 \mathrm{ml})$ developed. During hospitalization he had multiple episodes of infection. Repeated white cell counts showed the neutropenia ranging $35-1070 / \mathrm{mm}^{3}$. The bone marrow biopsy showed a maturation arrest of myelopoiesis.

At 8 months of age, a liver needle biopsy was performed. Histologic examination showed enlarged hepatocytes with PAS positive granules. These PAS positive materials disappeared after amylase treatment. Hepatic glycogen level was $9.1 \mathrm{~g} / 100 \mathrm{~g}$ of wet weight tissue.

Patient Y.M. is a 25-year-old woman. Hepatomegaly was first noticed at 4 years of age. Although a blood glucose determination was not done at that time, there were no symptoms suggesting hypoglycemia. Meanwhile, eruptive xanthoma appeared on both legs and hyperlipidemia was detected. At the age of 20 , she was admitted to Jichi Medical School Hospital for the examination of recurrent epistaxis which continued as long as $6 \mathrm{~h}$. Laboratory analysis suggested GSD type 1 and histology of liver biopsy confirmed liver GSD; however, hepatic glucose-6-phosphatase activity was normal in a frozen liver biopsy sample. A diagnosis of GSD type $1 \mathrm{~b}$ was made.

\section{MATERIALS AND METHODS}

A liver specimen was obtained by a needle biopsy from each patient. Control specimens were obtained at laparotomy from surgical patients. Informed consent was obtained from the patients or their parents. The 5\% liver homogenate was prepared immediately after biopsy in $0.25 \mathrm{M}$ sucrose solution containing $1 \mathrm{mM}$ EDTA, pH 7.0, and centrifuged for $10 \mathrm{~min}$ at $1650 \times \mathrm{g}$. The supernatants were divided into two portions: sodium taurocholate was added to one portion of supernatant (final concentration of $0.4 \mathrm{~g} / 100 \mathrm{ml}$ ), and the same volume of $0.25 \mathrm{M}$ sucrose was added to the other. Both supernatants were kept at $0^{\circ} \mathrm{C}$ for $30 \mathrm{~min}$. Sucrose solution $(0.25 \mathrm{M})$ was added to make $2.5 \%$ homogenates immediately before the various enzyme activities were determined. The modified method of Arion et al. (2) was used to determine phosphohydrolase activity. The standard assay mixture $(0.2 \mathrm{ml})$ contained $12 \mu$ mole of cacodylate buffer (pH 6.5 for G-6-P or M6-P phosphohydrolase and $\mathrm{pH} 6.0$ for PPi phosphohydrolase), 2 $\mathrm{mg}$ of bovine serum albumin, $60 \mu \mathrm{l}$ of the homogenate (equivalent to $1.5 \mathrm{mg}$ of wet weight of liver) and $4 \mu$ mole of G-6-P, $4 \mu$ mole of M-6-P or $2 \mu$ mole of PPi as substrate. The mixture was incubated at $30^{\circ} \mathrm{C}$ in a shaking water bath for $60 \mathrm{~min}$, if G-6-P or M-6-P was used as substrate and for $30 \mathrm{~min}$ if $\mathrm{PPi}$ was used as substrate. The reaction was terminated by adding $2.0 \mathrm{ml}$ of $3.5 \%$ trichloroacetic acid and the tubes were then placed in an ice bath for $5 \mathrm{~min}$. The released inorganic phosphate was determined on an aliquot of the trichloroacetic acid supernatant using the method of Fiske and Subbarrow (10). Homogenate and substrate blanks were prepared with each incubation and both blank values were subtracted for the calculations of the activity. Under the assay condition, the phosphohydrolase activities using G-6-P, M-6-P, or $\mathrm{PPi}$ as substrate were proportional to the amount of human liver extract, up to $2.0 \mathrm{mg}$ wet weight, in both untreated and taurocholate-treated (disrupted) homogenates. A linear correlation of product and incubation time was observed up to $80 \mathrm{~min}$ for G-6-P and M-6-P phosphohydrolase, and up to $45 \mathrm{~min}$ for PPi phosphohydrolase.

Untreated liver homogenates (UH) are composed of the "intact microsomes" and the small portions of the microsomes disrupted in the process of preparation. The theoretical activity for "intact microsomes" was calculated using an equation of Arion et al. (5).

$$
\mathrm{V}_{\mathrm{IM}}=\frac{V_{\mathrm{UH}}-\mathrm{V}_{\mathrm{DH}} \times \text { f.d.UH }}{1-\text { f.d.UH }}
$$

where $V_{I M}, V_{U H}$ and $V_{D H}$ refer to the phosphohydrolase activity ( $\mu \mathrm{mole} / \mathrm{min} / \mathrm{g}$ of liver) of "intact microsomes," untreated homogenates, and fully disrupted homogenates, respectively. Fractional disruption of untreated homogenates (f.d. UH) can be calculated by dividing the M-6-P phosphohydrolase activity of untreated homogenates $\left(\mathrm{V}_{\mathrm{UH}}^{\mathrm{M}} \mathrm{P}^{\mathrm{ase}}\right)$ by that of fully disrupted homogenates $\left(\mathrm{V}_{\mathrm{DH}}^{\mathrm{M} 6 \mathrm{Pase}}\right)$, i.e., f.d.UH $=\frac{\mathrm{V}_{\mathrm{UH}}^{\mathrm{MG} P a s e}}{\mathrm{~V}_{\mathrm{DH}}^{\mathrm{MGPase}}}$.

\section{RESULTS}

G-6-P phosphohydrolase activity. As shown in Table 1 , the activities in patients Y.S. and Y.M. were found to be markedly decreased in the untreated homogenates, whereas the enzyme activities in the disrupted preparations were higher than those in the controls. The phosphohydrolase activities of untreated homogenates are the combined activities of the "intact microsomes" (in which $100 \%$ of intrinsic enzyme is housed) and the small 
portions of the microsomes disrupted in the process of preparation. The latency of M-6-P phosphohydrolase activity, a good index of the intactness of the microsomal membranes (12), ranged from 82-96\% for the two patients with GSD type $1 b$ and for the controls. In order to compare the intrinsic enzyme activities among the preparations, the theoretic activities of the "intact microsomes" were calculated (see "Materials and Methods"). The activity of the "intact microsomes" in Y.M. was $0.85 \mu \mathrm{mole} / \mathrm{min} / \mathrm{g}$ of liver and none was detectable in Y.S. The latency was $100 \%$ in Y.S. and $90.7 \%$ in Y.M. On the other hand, the G-6-P phosphohydrolase activities of the patients with GSD type la were decreased in both the untreated and the disrupted homogenates, indicating a defect in the glucose-6-phosphatase itself.

Table 2. Hepatic pyrophosphate phosphohydrolase activities (umole $/ \mathrm{min} / \mathrm{g}$ wet weight) from patients with glycogen storage disease (GSD) type $\mathrm{Ib}$ and la, and controls

\begin{tabular}{|c|c|c|c|c|}
\hline \multirow[b]{2}{*}{ Subject } & \multicolumn{3}{|c|}{ Pyrophosphate phosphohydrolase activity } & \multirow[b]{2}{*}{ Latency $^{2}$} \\
\hline & $\begin{array}{c}\text { Untreated } \\
\text { homogenates }\end{array}$ & $\begin{array}{l}\text { "Intact micro- } \\
\text { some" }\end{array}$ & $\begin{array}{l}\text { Disrupted ho- } \\
\text { mogenates }\end{array}$ & \\
\hline \multicolumn{5}{|l|}{ GSD $1 b$} \\
\hline $\begin{array}{l}\text { Patient } \\
\text { Y.S. }\end{array}$ & 6.59 & 6.07 & 19.06 & 68.1 \\
\hline $\begin{array}{l}\text { Patient } \\
\text { Y.M. }\end{array}$ & 6.09 & 5.36 & 14.37 & 62.7 \\
\hline \multicolumn{5}{|l|}{ GSD la } \\
\hline 1 & 0.19 & & 0.20 & \\
\hline 2 & 0.20 & & 0.16 & \\
\hline \multicolumn{5}{|l|}{ Control } \\
\hline 1 & 2.62 & 2.33 & 5.89 & 60.3 \\
\hline 2 & 4.97 & 4.01 & 13.71 & 70.8 \\
\hline 3 & 3.76 & 2.76 & 10.81 & 74.4 \\
\hline 5 & 3.41 & 3.00 & 5.75 & 47.8 \\
\hline 6 & 5.63 & 4.04 & 12.81 & 68.5 \\
\hline $\begin{array}{l}\text { mean } \pm \\
\text { S.D. } \\
\text { in } \\
\text { con- } \\
\text { trols }\end{array}$ & $4.08 \pm 1.21$ & $3.23 \pm 0.77$ & $9.79 \pm 3.78$ & $64.4 \pm 10.6$ \\
\hline
\end{tabular}

\footnotetext{
' Calculated using the equation of Arion et al. (5) (see "Materials and Methods")

${ }^{2}$ Latency is defined as $\left[1-\frac{\text { activity in "intact microsomes" }}{\text { activity in disrupted homogenates }}\right] \times 100$.
}

$P P i$ phosphohydrolase activity. The activities of the PPi phosphohydrolase of Y.S. and Y.M. were higher than those of the controls regardless of whether or not taurocholate was present (Table 2). Pi translocase mediates a penetration of $\mathrm{PPi}$ into microsomes as well as $\mathrm{Pi}$ efflux (5). The data imply that the $\mathrm{Pi}$ translocase activity was normal in Y.S. and in Y.M.. The cases of GSD type la exhibited a markedly decreased ability to hydrolyze PPi in both the untreated and the disrupted preparations.

Kinetic studies. Kinetic analysis of G-6-P phosphohydrolase activities with preparations from Y.M. and from 4 controls were carried out. $\mathrm{Km}$ for G-6-P was calculated using Lineweaver-Burk plots in a range of substrate concentration between $1-100 \mathrm{mM}$ (Table 3). No significant change in $\mathrm{Km}$ values by taurocholate treatment from the controls were observed. When taurocholate was present, the $\mathrm{Km}$ value of the patient's G-6-P phosphohydrolase was also similar to those of the controls. Figure 1 shows Lineweaver-Burk plots of G-6-P phosphohydrolase activity of untreated homogenates from Y.M. and control \#5. The double reciprocal plots for the control were linear, although there was some inhibition by G-6-P at the concentrations above $50 \mathrm{mM}$. On the other hand, the data for Y.M. defined a straight line only at low concentrations $(1-5 \mathrm{mM})$, whereas at higher concentrations of G-6-P (10-100 mM) a substantial activation occurred. These data suggested that the untreated homogenates from Y.M. contain two components of G-6-P phosphohydrolase activity. When the data at the low substrate concentrations were extrapolated, the $\mathrm{Km}$ for G-6-P (low $\mathrm{Km}$ ) was approximately $5.3 \mathrm{mM}$. This is of same order as that found in the disrupted preparations from Y.M. or the controls (Table 3 ), suggesting that the low $\mathrm{Km}$ activity might be catalyzed by a component of the microsomes disrupted in the process of preparation. It is not likely that the higher activity

Table 3. Michaelis constants (mM) for glucose-6-phosphate phosphohydrolase activities

\begin{tabular}{lcccc}
\hline & \multicolumn{2}{c}{ Taurocholate absent } & & $\begin{array}{c}\text { Taurocholate } \\
\text { present }\end{array}$ \\
\cline { 2 - 3 } \multicolumn{1}{r}{ Subject } & Low Km & High Km & & Km \\
\hline Patient Y.M. & 5.26 & 100.0 & & 6.45 \\
Control & & & & \\
1 & 6.37 & absent & & 6.25 \\
2 & 5.00 & absent & & 6.25 \\
5 & 6.90 & absent & 7.14 \\
6 & 6.37 & absent & \\
\hline
\end{tabular}

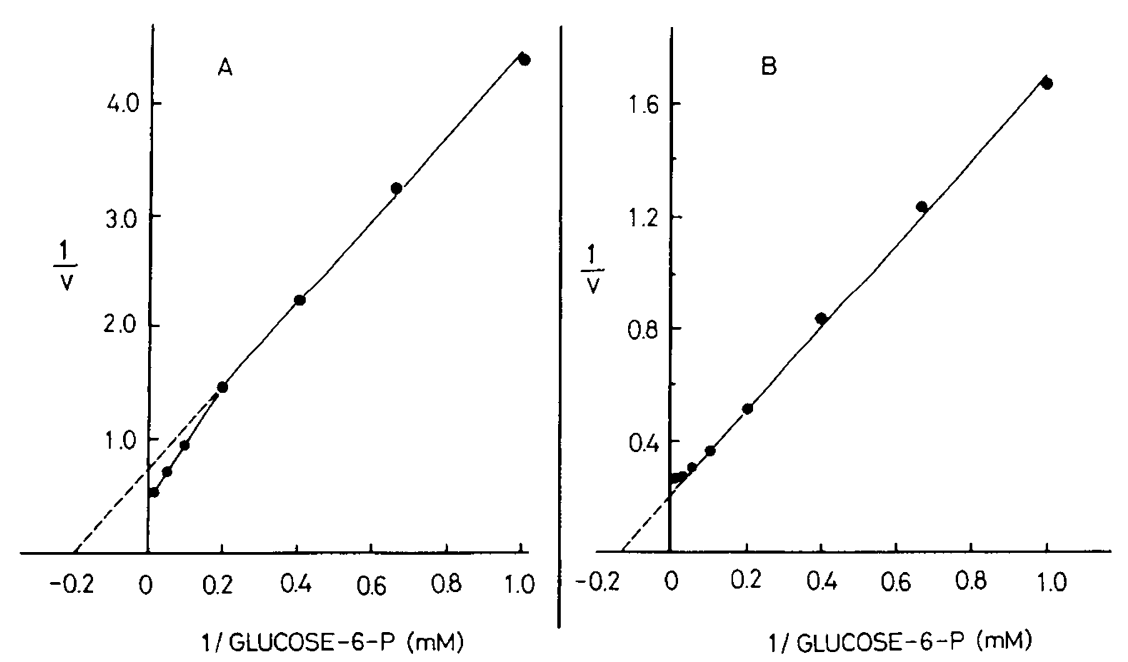

Fig. 1. Lineweaver-Burk plots of glucose-6-phosphate (G-6-P) phosphohydrolase activity and G-6-P concentration in untreated homogenates from patient Y.M. $(A)$ and control $\# 5(B)$. The total volume of the reagent mixture was $0.4 \mathrm{ml}$ containing $24 \mu$ mole of cacodylate buffer (pH 6.5$), 4 \mathrm{mg}$ of bovine serum albumin, $120 \mu$ lof the homogenates ( $3 \mathrm{mg}$ of wet weight liver) and concentrations of G-6-P ranging from 1.0 to $100 \mathrm{mM}$. 


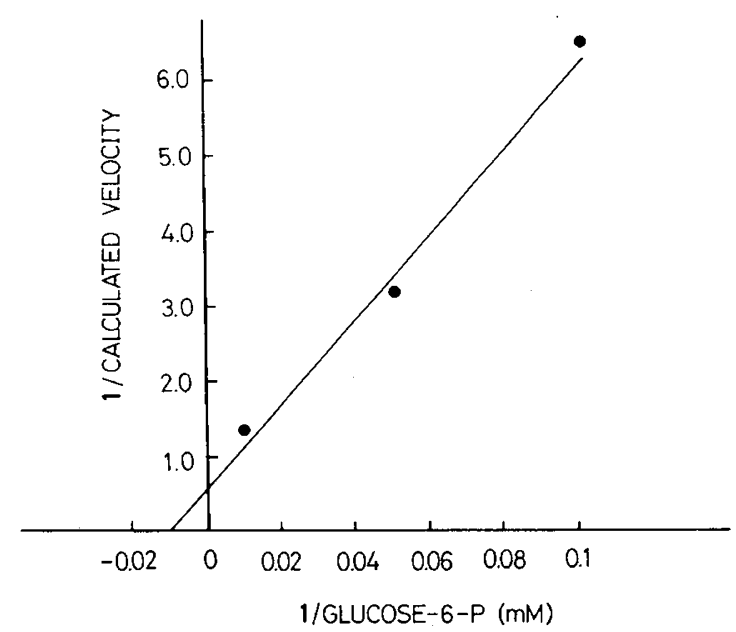

Fig. 2. Lineweaver-Burk plots of the high Km glucose-6-phosphate (G6-P) phosphohydrolase activity at concentrations of 10-100 G-6-P mM in untreated liver homogenates from patient Y.M..

at high concentrations of G-6-P was due to disruption of microsomes by high substrate concentrations, because the higher activity was not observed in Y.S.. The method of Arion et al. (4) was used in order to yield the kinetic characteristics of higher $\mathrm{Km}$ activity, i.e., the initial rates of the high $\mathrm{Km}$ activity were calculated by subtracting the contribution of the low $\mathrm{Km}$ component at concentrations of G-6-P between $10-100 \mathrm{mM}$ from the observed rate of the hydrolysis catalyzed by the untreated preparations. In the double reciprocal plots, the calculated data points were linear (Fig. 2). We assume that the untreated homogenates of Y.M. contain two G-6-P phosphohydrolase activities of markedly different $\mathrm{Km}$ and that the high $\mathrm{Km}$ activity is catalyzed by the glucose-6-phosphatase housed in the intact microsomes. The high $\mathrm{Km}$ was approximately $100 \mathrm{mM}$, this value was approximately 16 times higher than that of the controls.

\section{DISCUSSION}

In 1978 we suggested that the primary lesion of GSD type $1 b$ exists in the G-6-P transport system of the microsomal membrane $(11,14)$. Since then, there have been several reports in which a defect of the G-6-P transport system was confirmed $(7,9,12,20)$. We observed three patients with GSD type $1 \mathrm{~b}$ including two siblings. These patients showed a wide range of the clinical findings. The clinical symptoms in the siblings were severe compared to most patients with GSD type $1 \mathrm{~b}$ reported in the literature $(6-9,16,19,21,22)$, indicating an early onset and rapid development of hypoglycemia. The patients had neutropenia (15), which was common in cases of GSD type $1 b(1,6,7,13,17,18)$. On the other hand, the adult patient (Y.M.) had mild clinical symptoms; she did not have clinical symptoms of hypoglycemia, neutropenia and episodes of recurrent infections.

The G-6-P translocase can be regarded as the locus of the functional defect in the glucose-6-phosphatase in our patients because the G-6-P phosphohydrolase activities of "intact microsomes" were markedly decreased, whereas the PPi phosphohydrolase activities of "intact microsomes" were greater than those of the controls. The extent of residual activities of G-6-P translocase was different in the patients. One of siblings (Y.S.) revealed no detectable activity G-6-P translocase. The other patient had a markedly low activity $(11,14)$ because the latency of G-6-P phosphohydrolase activity was $92.3 \%$ without a correction based on the latency of M-6-P phosphohydrolase. The defect of G-6-P translocase was found to be partial in the adult patient (Y.M.). The clinical symptoms and enzymatic studies in the three patients suggest that the clinical severity of this disorder depends on the level of the residual activity of the G-6-P translocase.
The G-6-P phosphohydrolase in the untreated preparations from Y.M. has an apparent high $\mathrm{Km}$, which is 16 times higher than those of controls. Because the high $\mathrm{Km}$ disappeared after treatment with detergent, the apparent high $\mathrm{Km}$ might reflect the $\mathrm{Km}$ for the G-6-P translocase, the action of which precedes hydrolysis. The kinetic studies suggest that the deficiency in the G-6-P translocase activity in Y.M. was caused by structural abnormality of the enzyme.

The identification of the locus of the defect in the variants of GSD type 1 requires an assay for both the G-6-P and the PPi phosphohydrolase using both untreated and disrupted preparations of microsomes. The determination of M-6-P phosphohydrolase activity is also essential in order to calculate the phosphohydrolase activities for the "intact microsomes." Correcting the activity of the "intact microsomes" makes it possible to compare the function of glucose-6-phosphatase located in intact microsomes among patients. This systematic approach to the glucose-6phosphatase system has so far been performed only in a patient with GSD type $1 \mathrm{~b}$ by Lange et al. (12), who used liver microsomes prepared from fresh liver tissue. From the technical point of view, the determination of the enzyme activities clinically requires the use of methods which can be applied to small amounts of crude liver extracts. Our method requires only $15 \mathrm{mg}$ of tissues, obtainable by needle biopsy, for the measurement of all the three phosphohydrolase activities in both the untreated and the disrupted preparations.

\section{REFERENCES AND NOTES}

1. Anderson, D. C., Mace, M. L., Brinkley, B. R., Martin, R. R., and Smith, S. W.: Recurrent infection in glycogenosis type $1 \mathrm{~b}$ : Abnormal neutrophil motility related to impaired redistribution of adhesion sites. J. Infect. Dis., 143: 447 (1981).

2. Arion, W. J., Sallin, B. K., Carlson, P. W., and Lange, A. J.: The specificity of glucose-6-phosphatase of intact liver microsomes. J. Biol. Chem., 247: 2558 (1972).

3. Arion, W. J., Wallin, B. K., Lange, A. J., and Ballas, L. M.: On the involvement of a glucose 6-phosphate transport system in the function of microsomal glucose 6-phosphatase. Mol. Cell Biochem., 6: 75 (1975).

4. Arion, W. J., Ballas, L. M., Lange, A. J., and Wallin, B. K.: Microsomal membrane permeability and the hepatic glucose-6-phosphatase system. J. Biol. Chem., 251: 4901 (1976).

5. Arion, W. J., Lange, A. J., Walls, H. E., and Ballas, L. M.: Evidence for the participation of independent translocases for phosphate and glucose-6-phosphate in the microsomal glucose-6-phosphatase system. J. Biol. Chem., 255: 10396 (1980).

6. Bartram, C. R., Przyrembel, H., Wendel, U., Bremer, H. J., Schaub, J., and Haas, J. R.: Glycogenosis type $1 \mathrm{~b}$ complicated by severe granulocytopenia resembling inherited neutropenia. Eur. J. Pediatr., 137: 81 (1981)

7. Beaudet, A. L., Anderson, D. C., Michels, V. V., Arion, W. J., and Lange, A. J.: Neutropenia and impaired neutrophil migration in type $1 \mathrm{~B}$ glycogen storage disease. J. Pediatr., 97: 906 (1980).

8. Briggs, J. N. and Haworth, J. C.: Liver glycogen disease. Report of a case of hyperuricemia, renal calculi and no demonstrable enzyme defect. Am. J. Med., 36: 443 (1964).

9. Corbeel, L., Hue, L., Lederer, B., Barsy, T. D., Berghe, G. V. E., Devlieger, H., Jaeken, J., Bracke, P., and Eeckels, R.: Clinical and biochemical findings before and after portacaval shunt in a girl with type $1 \mathrm{~b}$ glycogen storage disease. Pediatr. Res., 15: 58 (1981).

10. Fiske, C. H. and Subbarrow, Y.: The colorimetric determination of phosphorus. J. Biol. Chem., 66: 375 (1925).

11. Igarashi, Y., Otomo, H., Narisawa, K., and Tada, K.: A new variant of glycogen storage disease type 1 probably due to a defect in the glucose-6-phosphate transport system. J. Inher. Metab. Dis., 2: 45 (1979).

12. Lange, A. J., Arion, W. J., and Beaudet, A. L.: Type $1 \mathrm{~b}$ glycogen storage disease is caused by a defect in the glucose-6-phosphate translocase of the microsomal glucose-6-phosphatase system. J. Biol. Chem., 255: 8381 (1980).

13. McCabe, E. R. B., Melvin, T. R., O'Brien, D., Montgomery, R. R., Robinson, W. A., Bhasker, C., and Brown, B. I.: Neutropenia in a patient with type 1B glycogen storage disease: In vitro response to lithium chloride. J. Pediatr., 97: 944 (1980).

14. Narisawa, K, Igarashi, $Y$., Otomo, $H$., and Tada, $K$.: A new variant of glycogen storage disease type 1 probably due to a defect in the glucose-6-phosphate transport system. Biochem. Biophys. Res. Commun., 83: 1360 (1978).

15. Narisawa, K., Tada, K., and Kuzuya, T.: Neutropenia in type $1 \mathrm{~B}$ glycogen storage disease. J. Pediatr., 99: 334 (1981).

16. Pagliara, A. S., Karl, I. E., Haymond, M., and Kipnis, D. M.: Hypoglycemia in infancy and childhood. Part II. J. Pediatr., 82: 558 (1973).

17. Ragab, A. H., Zarkowsky, H. S., Keating, J. P., and Pagliara, A. L.: The regulation of granulopoiesis in childhood neutropenic disorders and acute leukemia. Pediatr. Res., 8: 407 (1974). 
18. Roe, T. F.: Chronic neutropenia in glycogen storage disease (GSD) type $1 \mathrm{~b}$. Pediatr. Res., 15: 639 (1981).

19. Sann, L., Mathieu, M., Bourgeois, J., Bienvenu, J. and Bethenod, M.: In vivo evidence for defective activity of glucose-6-phosphatase in type $1 \mathrm{~B}$ glucogenosis. J. Pediatr., 96: 691 (1980).

20. Schaub, J., Bartholomé, K., Feist, D., and Schmidt, H.: Glycogenosis type lb. Further evidence for a membrane disease. Eur. J. Pediatr., 135: 325 (1981).

21. Senior, B. and Loridan, L.: Studies of liver glycogenosis, with particular reference to the metabolism of intravenously administrated glycerol. N. Engl. J. Med., 279: 958 (1968).

22. Sokal, J. E., Lowe, C. U., Sarcione, E. J., Mosovich, L. L., and Doray, B. H.:

Copyright $(\mathcal{C} 1983$ International Pediatric Research Foundation, Inc. $0031-3998 / 83 / 1707-0545 \$ 02.00 / 0$
Studies of glycogen metabolism in liver glycogen disease (von Gierke's disease): six cases with similar metabolic abnormalities and responses to glucagon. J. Clin. Invest., 40:364 (1961).

23. Requests for reprints should be addressed to: Kuniaki Narisawa, Department of Pediatrics, Tohoku University School of Medicine, 1-1 Seiryo-cho, Sendai 980, Japan.

24. This research was supported by Grant-in Aid for Scientific Research from the Ministry of Education, Science and Culture, and by Grants from the Ministry of Public Welfare, Japan.

25. Received for publication July 22, 1982.

26. Accepted for publication November 4, 1982 